\title{
Stability Assessment of Single-Cross Maize Hybrids Using GGE-Biplot Analysis
}

\author{
L. Musundire ${ }^{1,2,3}$, J. Derera ${ }^{4}$, S. Dari ${ }^{5}$, A. Lagat ${ }^{2,3}$ \& P. Tongoona ${ }^{6}$ \\ ${ }^{1}$ Seed Co. International Ltd., Potchefstroom, South Africa \\ ${ }^{2}$ International Maize and Wheat Improvement Center, Nairobi, Kenya \\ ${ }^{3}$ ICRAF House, United Nations Avenue, Nairobi, Kenya \\ ${ }^{4}$ School of Agricultural, Earth and Environmental Sciences, University of KwaZulu-Natal, Pietermaritzburg, \\ South Africa \\ ${ }^{5}$ Crop Science Department, Faculty of Agriculture, University of Zimbabwe, Harare, Zimbabwe \\ ${ }^{6}$ West African Centre for Crop Improvement, University of Ghana, Ghana \\ Correspondence: Lennin Musundire, Seed Co. International Ltd., Haaskraal 460, Potchefstroom, 2520, South \\ Africa; International Maize and Wheat Improvement Center (CIMMYT), Nairobi, Kenya; ICRAF House, United \\ Nations Avenue, Nairobi, Kenya. Tel: 27-769-234-761; 254-748-458-933. E-mail: 1.musundire@cgiar.org; \\ lenninmusun@yahoo.com
}

Received: December 5, 2020

Accepted: January 4, $2021 \quad$ Online Published: January 15, 2021

doi: $10.5539 /$ jas.v13n2p78

URL: https://doi.org/10.5539/jas.v13n2p78

\begin{abstract}
Grain yield potential of new maize hybrid varieties across target environments contributes to the uptake of these varieties by farmers. Evaluation of single-cross hybrids developed from test crossing introgressed inbred lines bred for three distinct environments to elite tropical inbred line testers was carried out. The study's objective was to assess grain yield stability and genotype adaptability of the single-cross hybrids across South African environments relative to adapted commercial hybrid checks. One hundred and twenty-two introgressed inbred lines developed using the pedigree breeding program were crossed to four tropical elite inbred line testers using line $\times$ tester mating design to obtain 488 experimental single cross hybrids. Subject to availability of adequate seed for evaluation, a panel of 444 experimental single-cross hybrids was evaluated using an augmented design in two experiments defined as Population A and B for the study's convenience in South African environments. Data for grain yield ( $\mathrm{t} / \mathrm{ha}$ ) performance for experimental single-cross hybrids and commercial check hybrids in Population A and B across environments and individual environments identified experimental single-cross hybrids that had significant comparable grain yield ( $\mathrm{t} / \mathrm{ha}$ ) performance relative to best commercial check hybrid (PAN6Q445B) on the market. The selected experimental single-cross hybrids 225, 89, 246 and 43 (Population A) and 112 (Population B) also had a better average rank position for grain yield (t/ha) relative to best commercial check hybrid. These selected experimental single-cross hybrids had a grain yield ( $\mathrm{t} / \mathrm{ha}$ ) advantage range of 0.9-6.7\% for Population A and 7.3\% for Population A and B, respectively, relative to the adapted commercial check hybrid. GGE biplot patterns for which won-where for Population A indicated that at Potchefstroom Research Station and Ukulinga Research Station experimental single-cross hybrids 127 and135 were the vertex (winning) hybrids. Cedera Research Station did not have a vertex hybrid for Population A. For Population B, experimental single-cross hybrids 112, 117 and 18 were the vertex hybrids at Cedera Research Station, Ukulinga Research Station and Potchefstroom Research Station, respectively. Experimental single-cross hybrid 257 was identified as ideal genotype for Population A, while experimental single-cross hybrid 121 in Population B was the ideal genotype. Ideal environments were also identified as Ukulinga Research Station for Population A, and Cedera Research Station for Population B. Average-environment coordination (AEC) view of the GGE biplot in Population A indicated that experimental single-cross hybrids 1 was highly stable across environments. In comparison, Population B experimental single-cross hybrid 161 was highly stable across environments. In conclusion, selected single-cross hybrids in the current study can also be advanced for further evaluation with a possibility for identifying high yielding and stable single-cross hybrids for variety registration and release in target environments in South Africa.
\end{abstract}


Keywords: maize hybrids, GGE-biplots, genotype, genotype-environment interaction

\section{Introduction}

In developing countries, particularly in Africa, maize (Zea mays L.) is a critical and strategic cereal crop grown across many of its regions. Its wide adaptability in target environments has rendered it a staple food crop across tropical, subtropical, and temperate regions of the world. In South Africa, a predominantly warm temperate environment, maize is the largest locally produced field crop with increasing food, feed, and industrial usage value for the population (Syngenta Foundation for Sustainable Agriculture, 2020). Maize is also regarded as a net earner of foreign currency for the South African economy. Therefore, South Africa maize production is a large and lucrative market for breeding programmes operating inside and outside South Africa. An indication that breeding programmes should ensure the release of stable maize hybrid varieties that perform well in the South African warm temperate environments, aiming for broad adoption by farmers.

In maize breeding, the primary objective is to develop hybrids with high yield potential and adaptability across target environments. According to Kuchanur et al. (2015), breeders should select top grain yielding genotypes associated with high grain yield stability. Mostafavi et al. (2011), and Elias et al. (2016) report that targeting improved varieties to specific environments is difficult when genotype-by-environment interaction is present since yield is less predictable be interpreted based only on genotype and environment means. Genotype-by-environment interaction is here defined as the differential ranking of variety yields across target environments, resulting in the variable performance of hybrid varieties in selected target environments (Crossa et al., 2002; Jandong et al., 2011; Heidari et al., 2016). Thus, it complicates the utilization of hybrid maize varieties across target environments.

In this study, the emphasis is on identifying improved tropical introgressed maize inbred line hybrid combinations capable of maximizing maize production potential in South African warm temperate environments and farming systems, thus reducing crop failure or low incidences grain yields in unfavourable seasons. Breeding programmes have to develop improved maize varieties for the farmers with excellent agronomic performance relative to adapted commercial check varieties in the target environments. Recommendation of improved hybrid varieties in target environments requires these genotypes to be evaluated in several different but representative environments to identify consistently high-yielding and relatively stable genotypes and areas of specific adaptation (Balestre et al., 2009; Setimela et al., 2017).

A few methods have been applied in maize breeding programmes to evaluate cultivars' adaptability and stability in target environments. Two main approaches have been consistently used in several studies, namely: additive main effects and multiplicative interaction (AMMI) analysis (George \& Lundy 2019; Gauch et al., 2008; Gauch, 2006; Duarte \& Vencovsky, 1999); and a modification of the conventional AMMI analysis called genotype (G) and genotype-by-environment interaction (GE) (GGE-biplot) analysis (Yan \& Tinker, 2006; Kaya et al., 2006; Yan et al., 2000). AMMI and GGE-biplot provide breeders with tools to measure maize hybrid varieties' response efficiently and accurately in multiple test environments (Yan et al., 2007). According to Balestre et al. (2009), AMMI analysis interprets the effects of genotypes and environments as an additive and GE interaction as a multiplicative principal component analysis. The GGE-biplot analysis groups the genotype effects, which are additive in the AMMI analysis, together with the GE interaction multiplicative effects and analyses these effects by principal components (Kaya et al., 2006). According to Yan and Hunt (2001), and Yan et al. (2007), GGE, biplot software is an excellent visual MET data analysis tool. Compared with conventional methods of the MET data analysis, the GGEbiplot approach has some advantages. The first advantage of the biplot is its graphical presentation of the MET data, which significantly enhances our ability to understand the data patterns. The second is that it is more interpretative. It facilitates pair-wise genotype comparisons. The third advantage of this method is that it enables the identification of possible mega-environments.

Genotype and genotype-by-environment interaction analysis were carried out in the current study on single-cross maize hybrid maize varieties to compare the grain yield potential of these genotypes across target environments relative to adapted commercial check entries. The comparison of grain yield potential of the maize genotypes at different environments or groups of environments in South African regions ensured the identification and recommendation of genotypes with higher grain yield potential in each target environment. As a breeder, the main objective is to breed for high grain yield potential. For that high grain yield potential to be highest or close to the highest, consistently in all locations within the geographical area for which variety will be released (Yan \& Tinker, 2006). The study's objective was to assess grain yield stability and genotype adaptability of single-cross hybrids, including parents, developed for three distinct mega environments, using GGE biplot analysis across the South African warm temperate environments relative to adapted commercial hybrid checks. 


\section{Method}

\subsection{Germplasm Development}

\subsubsection{Introgressed Inbred Lines Development}

Introgressed inbred lines used to generated experimental single-cross hybrids evaluated in the current study were developed from a pedigree breeding program. A single common donor maize parental inbred line (08CED6_7_B) from South Africa was used to introgress genes from temperate germplasm into 12 elite tropical inbred lines from Zimbabwe through pedigree crosses in 2008 in South Africa. Tropical maize inbred lines used were representative of the major tropical heterotic groups, mainly N3 (derived from Salisbury white), SC (Southern Cross which was derived from an open-pollinated population grown by Mr South in Zimbabwe), and P (derived from the open-pollinated variety (OPV) Potchefstroom Pearl). The temperate maize population was one of the major temperate heterotic groups used in South Africa (TAB population). Hand crossings were made between the tropical and temperate populations to generate $F_{1}$ hybrid seed. Due to challenges in flowering synchronization (nicking) and seed availability, a total of eight populations were generated for advancement and selection at $\mathrm{F}_{2}$ generation. Each population was independently advanced from $\mathrm{F}_{3}-\mathrm{F}_{6}$ generation through selfing and selection of adapted segregants to produce 122 introgressed inbred lines.

\subsubsection{Experimental Single-Cross Hybrids Development}

Experimental single-cross hybrids used in the current study were generated from testcrossing 122 Introgressed inbred lines to four tropical elite inbred line testers T1, T2, T3, and T4 using line by tester mating design. The four tropical elite inbred line testers used represented maize germplasm from two tropical heterotic groups $\mathrm{P}$ and N. A total of 488 experimental single-cross hybrids were produced from the test crossing. Subject to availability of adequate seed for evaluation, a panel of 444 experimental single-cross hybrids were evaluated using an augmented experimental design. Due to the large number (444) of the experimental single-cross hybrids involved and for convenience of the study, the experimental single-cross hybrids were divided into two populations that were designated population $\mathrm{A}$ and $\mathrm{B}$, with both populations related to heterotic groups $\mathrm{P}$ and $\mathrm{N}$. Population A comprised 280 experimental single-cross hybrids including four commercial hybrid checks; temperate hybrids (PAN3Q740 and PAN6Q445B) and tropical hybrids (PAN67 and SC633) to give a total evaluating panel of 284 entries. Population B consisted of 164 experimental single-cross hybrids, including three commercial hybrid checks (PAN6611, PAN6Q445B, and SC633) to give a total evaluating panel of 167 entries. Commercial check hybrids used in both populations were single-cross hybrids that are predominantly used in the South African market.

\subsection{Experimental Design and Trial Management}

A total of five trials were planted in three locations in South Africa environments. Table 1 presents a summary of the locations. In population A, 284 entries (experimental single-cross hybrids and commercial hybrid checks) were randomly assigned into 20 blocks; in each block, 14 experimental single-cross hybrids and two repeating checks (PAN3Q740 and PAN67) were randomly assigned to each block. Due to limited seed, commercial check hybrid entries SC633, PAN6227, and PAN6Q445B were randomly assigned into blocks as non-repeating commercial checks. In population B, 162 entries (experimental single cross hybrids and commercial checks) were randomly assigned into 16 blocks; in each block, ten experimental single-cross hybrids were included with two repeating commercial checks (PAN6611 and PAN6Q445B). Due to limited seed, non-repeating commercial check SC633 was randomly assigned into the blocks. Population A was replicated over two sites, namely Ukulinga and Cedara Research Stations. In comparison, Population B was replicated over three locations: Ukulinga, Cedara, and Potchefstroom Research Station. An augmented experimental design was used to evaluate the trial (Lin \& Poushinsky, 1983; Scott \& Milliken, 1993; Spehar, 1994). Due to the limited availability of seed, all experiments across sites were each planted as single-row plots. At Ukulinga Research Station, each entry was planted to $5 \mathrm{~m}$ length, spaced at $0.3 \mathrm{~m}$ in-row and $0.75 \mathrm{~m}$ between row spacing to achieve a total plant population density of at least 44000 plants ha ${ }^{-1}$. At Cedara Research Station, $5 \mathrm{~m}$ row-plots, in-row spacing 0.3 , and row spacing of $0.9 \mathrm{~m}$ were used to achieve a plant stand of at least 37000 plants ha ${ }^{-1}$. While at Potchefstroom Research Station, $6.6 \mathrm{~m}$ length, spaced at $0.25 \mathrm{~m}$ in-row, and $1.5 \mathrm{~m}$ between row spacing were employed to

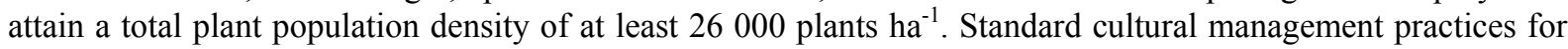
growing maize were carried out at all the sites. Irrigation was only applied to achieve uniform establishment and to supplement rainfall as and when necessary. Fertilizer was applied at a rate of $120 \mathrm{~kg}$ Nitrogen $(\mathrm{N}), 33 \mathrm{~kg}$ Phosphorous (P), and $44 \mathrm{~kg}$ Potassium (K) at Cedara, Ukulinga, and Potchefstroom Research Stations. 


\subsection{Measurements}

Data was collected at all the sites applying standard procedures used at International Maize and Wheat Improvement Centre (CIMMYT, 1985) for the following traits: days to anthesis and silking days were recorded when $50 \%$ of the plants were shedding pollen, and $50 \%$ of the plants had silks emerged, respectively; plant and ear height were measured before harvesting on five representative plants per plot; percentage stalk and root lodging was recorded as a percentage of plants per plot that had their stems broken and percentage of plants per plot which had their stems inclined at least $45^{\circ}$, respectively; and the number of ears per plant-ear prolificacy (EPP) was calculated as the count of the number of ears plot as a fraction of the total number of plants in the plot. All plants were hand-harvested and shelled grain weight was measured. Grain weights were adjusted to $12.5 \%$ moisture content and $80 \%$ shelling percentage to calculate grain yield $\left(\mathrm{t} \mathrm{ha}^{-1}\right)$.

\subsection{GGE Biplots}

Genotype and genotype-environment interaction GGE-biplot analysis were carried out on yield data only. In future publications, we will report on the other traits measured. The GGE- biplot concept (Yan et al., 2000) was used to visualize the multi-environment trials (MET) data, as reported by Kaya et al. (2006). The GGE-biplot showed the first two principal components (PC1 and PC2) derived from subjecting environmental-centred yield data (yield evaluation due to GGE) to singular value decomposition (Yan et al., 2000). In the current study, genotype-focused scaling was used for visualizing genotypic comparison, with environment-focused scaling for environmental comparison using GGE-biplots (GenStat 14 edition, 2013). A mixed model for LSD analysis was also carried out for multi-treatment comparison using the Tukey-Kramer method (Yu, 2010) to compare experimental single-cross hybrids and commercial check hybrids grain yield $(\mathrm{t} / \mathrm{ha})$ performance at individual sites and across sites.

Table 1. Summary of geographic location and season-related characteristics of the three trial locations

\begin{tabular}{|c|c|c|c|c|c|c|c|c|c|}
\hline Location & Latitude & Longitude & Coordinates & $\begin{array}{l}\text { Altitude } \\
\text { (m.a.s.l.) }\end{array}$ & Description (units) & $\mathbf{A}$ & B & Type of stress & Mega Environment \\
\hline \multirow{5}{*}{ Ukulinga } & \multirow{5}{*}{$29^{\circ} 37^{\prime} \mathrm{S}$} & \multirow{5}{*}{$30^{\circ} 16^{\prime} \mathrm{E}$} & \multirow{5}{*}{$\begin{array}{l}(-29.617 \\
20,267)\end{array}$} & \multirow{5}{*}{812} & Av max temp $\left({ }^{\circ} \mathrm{C}\right)$ & 25.9 & 24 & Heat and drought stress & $\begin{array}{l}\text { Coast hinterland } \\
\text { thornveld South } \\
\text { Africa mega } \\
\text { environment }\end{array}$ \\
\hline & & & & & Av min temp $\left({ }^{\circ} \mathrm{C}\right)$ & 16 & 12.9 & Increased cold soil temperature & $\begin{array}{l}\text { Margin of } \\
\text { Mid-Altitude } \\
\text { (>800 m.a.s.1.) } \\
\text { and lowland } \\
\text { (<800 m.a.s.1.) } \\
\text { CIMMYT mega } \\
\text { environment }\end{array}$ \\
\hline & & & & & & & & Increased frost exposure & \\
\hline & & & & & Rainfall (mm) & 600.7 & 885 & Grey leaf spot (GLS) & \\
\hline & & & & & & & & Long day length & \\
\hline \multirow{3}{*}{ Cedara } & \multirow{3}{*}{$26^{\circ} 32^{\prime} \mathrm{S}$} & \multirow{3}{*}{$30^{\circ} 16^{\prime} \mathrm{E}$} & \multirow{3}{*}{$\begin{array}{l}(-25.533, \\
30.267)\end{array}$} & \multirow{3}{*}{1068} & Av max temp $\left({ }^{\circ} \mathrm{C}\right)$ & 25.2 & 23.6 & Northern leaf corn blight (NCLB) & $\begin{array}{l}\text { Moist Midlands } \\
\text { Misbelt South Africa } \\
\text { mega environment }\end{array}$ \\
\hline & & & & & Av min temp $\left({ }^{\circ} \mathrm{C}\right)$ & 13 & 9.6 & Phaeosphaeria leaf spot (PLS) & $\begin{array}{l}\text { Mid-Altitude humid, } \\
\text { warm CIMMYT } \\
\text { mega environment }\end{array}$ \\
\hline & & & & & Rainfall (mm) & 647 & 873 & $\begin{array}{l}\text { Grey leaf spot (GLS) } \\
\text { Long day length }\end{array}$ & \\
\hline \multirow{3}{*}{ Potchefstroom } & \multirow{3}{*}{$26^{\circ} 73^{\prime} \mathrm{S}$} & \multirow{3}{*}{$27^{\circ} 75^{\prime} \mathrm{E}$} & \multirow{3}{*}{$\begin{array}{l}(-26.117 \\
28.250)\end{array}$} & \multirow{3}{*}{1349} & Av max temp $\left({ }^{\circ} \mathrm{C}\right)$ & 27.7 & 25.7 & $\begin{array}{l}\text { Heat and drought stress, } \\
\text { rain poorly distributed in } \\
\text { the season }\end{array}$ & $\begin{array}{l}\text { North-west dryland } \\
\text { South Africa mega } \\
\text { environment }\end{array}$ \\
\hline & & & & & Av min temp $\left({ }^{\circ} \mathrm{C}\right)$ & 19.5 & 9.8 & Phaeosphaeria leaf spot (PLS) & $\begin{array}{l}\text { Mid-Altitude } \\
\text { dryland CIMMYT } \\
\text { mega environment }\end{array}$ \\
\hline & & & & & Rainfall $(\mathrm{mm})$ & 708.7 & 703.1 & long day length & \\
\hline
\end{tabular}

Source: Ukulinga-Ukulinga Research Centre; Cedera-Cedera Research Station; Potchefstroom-Potchefstroom Research Station. 


\section{Results}

\subsection{Grain Yield (t/ha) Performance for Top 12\% High-Yielding Hybrids in Population A}

Data from grain yield ( $\mathrm{t} / \mathrm{ha}$ ) performance for top $12 \%$ top-yielding experimental single-cross hybrids and commercial check hybrids in Population A sorted according to the average rank for grain yield ( $t / h a)$ across sites and individual sites (Cedera Research Station, Potchefstroom Research Station and Ukulinga Research Centre environments) are presented in Table 2. Across the environments, data indicated that grain yield ( $\mathrm{t} / \mathrm{ha})$ performance was highly significant with experimental single-cross hybrids and adapted commercial check hybrids showing significant similar grain yield ( $t / h a)$ performance. The average rank position across environments for grain yield ( $t / h a)$ showed that the top four $(225,89,246$, and 43$)$ experimental single-cross hybrids had better grain yield $(\mathrm{t} / \mathrm{ha})$ rank position and higher grain yield $(\mathrm{t} / \mathrm{ha})$ equivalent to a range of 0.9 to $6.7 \%$ than the best adapted temperate environment commercial check hybrid (PAN6Q445B).

Individual environments, data for Cedera Research Station, Potchefstroom Research Station, and Ukulinga Research Centre environments grain yield ( $/$ ha) were significant with experimental hybrids illustrating comparable performance relative to the adapted temperate environment commercial check hybrids (PAN6Q445B, PAN3Q740, and PAN6227). At Cedera Research Station environment, the average rank position for grain yield $(\mathrm{t} / \mathrm{ha})$ highlighted that eleven experimental single-cross hybrids $(60,257,131,61,144,259,43,225,45$, 1, and 92) had a better average rank position placement than the best adapted temperate commercial check hybrid (PAN6Q445B). These eleven experimental single-cross hybrids had a grain yield ( $t / \mathrm{ha}$ ) advantage that ranged from 0.4 to $12.1 \%$ relative to the best adapted temperate commercial check hybrid (PAN6Q445B). Similarly, at Ukulinga Research Centre environment, fourteen experimental single-cross hybrids $(135,257,61,225,1,138$, $89,259,255,245,253,263,137$, and 144) had high average range position for grain yield ( $t /$ ha) relative to best adapted commercial check hybrid (PAN6Q445B). A grain yield ( $\mathrm{t} / \mathrm{ha}$ ) advantage of between 4.4 to $97.9 \%$ was noted over the best adapted commercial check (PAN6Q445B). Equally, the Potchefstroom Research Station environment exhibited a similar trend with three experimental single-cross hybrid entries $(225,89$, and 246) exhibiting high average range position for grain yield ( $\mathrm{t} / \mathrm{ha}$ ) relative to best adapted temperate commercial check hybrid (PAN6Q445B). The grain yield advantage over the best adapted commercial check hybrid (PAN6Q445B) ranges from 3.16 to $3.86 \%$. The grain yield ( $\mathrm{t} / \mathrm{ha}$ ) performance data for across environments and individual environments illustrate Genotype $\times$ Environment $(\mathrm{G} \times \mathrm{E})$, as under various environments (Cedera Research Station, Potchefstroom Research Station, and Ukulinga Research Centre) not the same hybrid entries out yielded the best commercial check hybrids in terms of grain yield (t/ha) rank placement. This data is further supported by genotype main effects $(\mathrm{G})$ and genotype $\times$ environment interaction effects model, known as GGE biplots Figures 1 to 8. The GGE model applies the singular value decomposition (SVD) to the data, subtracting the environmental effects because the biplots display both G and GE, which are the two sources of variation relevant to cultivar variation (Frutos et al., 2014). 
Table 2. Grain yield (t/ha) performance for $12 \%$ of the top-yielding single-cross hybrids and commercial check hybrids in Population A entries across and individual environments

\begin{tabular}{|c|c|c|c|c|c|c|c|c|c|c|c|}
\hline Entry & Across & A1 & Entry & Cedera & A1 & Entry & Ukulinga & A1 & Entry & Potchefstroom & A1 \\
\hline 225 & $10.42 \mathrm{a}$ & 6.68 & 60 & $14.39 \mathrm{a}$ & 12.09 & 135 & $18.11 \mathrm{a}$ & 97.87 & 225 & $1.49 \mathrm{a}$ & 3.86 \\
\hline 89 & $10.33 \mathrm{a}$ & 5.73 & 257 & $14.09 \mathrm{a}$ & 9.75 & 257 & $14.36 \mathrm{ab}$ & 56.89 & 89 & $1.48 \mathrm{ab}$ & 3.16 \\
\hline 246 & $10.29 \mathrm{a}$ & 5.29 & 131 & $13.79 \mathrm{a}$ & 7.42 & 61 & 13.96ab & 52.51 & 246 & $1.48 \mathrm{ab}$ & 3.16 \\
\hline 43 & $9.86 \mathrm{ab}$ & 0.96 & 61 & $13.49 \mathrm{a}$ & 5.08 & 225 & $13.21 \mathrm{ab}$ & 44.32 & 43 & $1.42 \mathrm{abcd}$ & -0.68 \\
\hline 75 & $9.57 \mathrm{abc}$ & -2.04 & 144 & $13.24 \mathrm{a}$ & 3.13 & 1 & $11.56 \mathrm{ab}$ & 26.28 & 45 & $1.38 \mathrm{abcdef}$ & -3.83 \\
\hline 45 & 9.49abc & -2.89 & 259 & $13.24 \mathrm{a}$ & 3.13 & 138 & $11.31 \mathrm{ab}$ & 23.55 & 41 & 1.34abcdefg & -6.63 \\
\hline 41 & $9.15 \mathrm{abcd}$ & -6.35 & 43 & $13.19 \mathrm{a}$ & 2.75 & 89 & $10.81 \mathrm{ab}$ & 18.09 & 75 & 1.34abcdefg & -6.63 \\
\hline 256 & 8.97abcde & -8.19 & 225 & $13.19 \mathrm{a}$ & 2.75 & 259 & $10.81 \mathrm{ab}$ & 18.09 & 256 & 1.34abcdefg & -6.63 \\
\hline 253 & 8.89abcde & -8.96 & 45 & $13.14 \mathrm{a}$ & 2.36 & 255 & $10.51 \mathrm{ab}$ & 14.81 & 108 & 1.27abcdefgh & -11.17 \\
\hline 271 & 8.85abcdef & -9.37 & 1 & $12.94 \mathrm{a}$ & 0.80 & 245 & $10.36 \mathrm{ab}$ & 13.17 & 253 & 1.27abcdefgh & -11.17 \\
\hline 61 & 8.82abcdef & -9.73 & 92 & $12.89 \mathrm{a}$ & 0.41 & 253 & $10.01 \mathrm{ab}$ & 9.34 & 263 & 1.27abcdefghi & -11.52 \\
\hline 138 & 8.81 abcdef & -9.86 & 127 & $12.84 \mathrm{a}$ & 0.02 & 263 & $9.96 \mathrm{ab}$ & 8.80 & 240 & 1.26abcdefghi & -11.87 \\
\hline 137 & 8.78abcdef & -10.18 & 135 & $12.79 \mathrm{a}$ & -0.37 & 137 & $9.66 \mathrm{ab}$ & 5.52 & 271 & 1.25abcdefghi & -12.57 \\
\hline 263 & $8.75 \mathrm{abcdef}$ & -10.44 & 137 & $12.79 \mathrm{a}$ & -0.37 & 144 & $9.56 \mathrm{ab}$ & 4.43 & 138 & 1.25abcdefghij & -12.92 \\
\hline 240 & 8.73abcdef & -10.66 & 75 & $12.49 \mathrm{a}$ & -2.71 & 246 & $8.91 \mathrm{ab}$ & -2.68 & 137 & 1.21abcdefghij & -15.37 \\
\hline 245 & 8.64abcdefg & -11.52 & 41 & $12.14 \mathrm{ab}$ & -5.43 & 75 & $8.81 \mathrm{ab}$ & -3.77 & 61 & 1.20abcdefghij & -16.42 \\
\hline 108 & 8.55abcdefg & -12.49 & 246 & $12.14 \mathrm{ab}$ & -5.43 & 271 & $8.51 \mathrm{ab}$ & -7.05 & 245 & 1.20abcdefghij & -16.42 \\
\hline 92 & 8.41abcdefg & -13.91 & 139 & $10.49 \mathrm{ab}$ & -18.28 & 43 & $7.91 \mathrm{ab}$ & -13.61 & 259 & 1.19abcdefghij & -16.77 \\
\hline 259 & 8.31abcdefg & -14.96 & 89 & $10.44 a b$ & -18.67 & 108 & $7.71 \mathrm{ab}$ & -15.79 & 134 & 1.18abcdefghij & -17.81 \\
\hline 127 & 8.19abcdefg & -16.13 & 240 & $10.19 \mathrm{ab}$ & -20.62 & 60 & $7.36 \mathrm{ab}$ & -19.62 & 127 & 1.15abcdefghij & -19.91 \\
\hline 257 & 8.18abcdefg & -16.28 & 253 & $9.84 \mathrm{ab}$ & -23.35 & 45 & $7.11 \mathrm{ab}$ & -22.35 & 92 & 1.11abcdefghij & -22.36 \\
\hline 60 & 7.95abcdefg & -18.72 & 134 & $9.59 \mathrm{ab}$ & -25.29 & 41 & $6.81 \mathrm{ab}$ & -25.63 & 257 & 1.11abcdefghijk & -22.71 \\
\hline 134 & 7.81abcdefg & -20.02 & 263 & $9.39 \mathrm{ab}$ & -26.85 & 154 & $6.71 \mathrm{ab}$ & -26.72 & 131 & 1.09abcdefghijk & -24.11 \\
\hline 131 & 7.64abcdefg & -21.72 & 245 & $8.44 \mathrm{ab}$ & -34.25 & 92 & $6.46 \mathrm{ab}$ & -29.45 & 154 & 1.08abcdefghijk & -24.81 \\
\hline 1 & 7.43abcdefg & -23.93 & 256 & $8.34 \mathrm{ab}$ & -35.03 & 134 & $6.31 \mathrm{ab}$ & -31.09 & 60 & 1.07abcdefghijk & -25.16 \\
\hline 154 & 7.25abcdefg & -25.80 & 271 & $7.69 \mathrm{ab}$ & -40.09 & 240 & $5.81 \mathrm{ab}$ & -36.56 & 1 & 1.03abcdefghijkl & -28.30 \\
\hline 135 & 7.00abcdefgh & -28.34 & 154 & $7.64 \mathrm{ab}$ & -40.48 & 131 & $5.56 \mathrm{ab}$ & -39.29 & 135 & 0.97abcdefghijkl & -32.15 \\
\hline 144 & 5.30abcdefgh & -45.74 & 108 & $7.59 \mathrm{ab}$ & -40.87 & 127 & $2.16 \mathrm{ab}$ & -76.45 & 144 & 0.71 abcdefghijkl & -50.68 \\
\hline Mean of Population & 6.70abcdefgh & & & $12.79 \mathrm{a}$ & & & $9.15 \mathrm{ab}$ & & & 0.96 abcdefghijkl & \\
\hline Check 3 (SC633) & 8.49abcdefg & & & $11.64 \mathrm{ab}$ & & & $9.21 \mathrm{ab}$ & & & 1.16abcdefghij & \\
\hline Check 5 (PAN6227) & 6.97abcdefgh & & & $9.34 \mathrm{ab}$ & & & $7.21 \mathrm{ab}$ & & & 0.99abcdefghijk1 & \\
\hline Check 4 (PAN6Q445B) & $9.77 \mathrm{abc}$ & & & $12.84 \mathrm{a}$ & & & $9.01 \mathrm{ab}$ & & & $1.43 \mathrm{abc}$ & \\
\hline Check 1 (PAN3Q740) & 5.30abcdefgh & & & $5.88 \mathrm{ab}$ & & & $9.15 \mathrm{ab}$ & & & 0.76abcdefghijkl & \\
\hline Check 2 (PAN67) & 8.28abcdefg & & & $11.11 \mathrm{ab}$ & & & $9.47 \mathrm{ab}$ & & & 1.18abcdefghij & \\
\hline Mean of checks & 7.76abcdefg & & & $10.16 \mathrm{ab}$ & & & $8.81 \mathrm{ab}$ & & & 1.10abcdefghijk & \\
\hline $\operatorname{LSD}(0.05)$ & 0.12 & & & 0.1 & & & 0.12 & & & 0.01 & \\
\hline $\mathrm{CV}$ & 20.71 & & & 14.79 & & & 17.38 & & & 10.95 & \\
\hline Std Dev & 4.67 & & & 1.17 & & & 3.26 & & & 0.22 & \\
\hline Std Error & 0.9 & & & 0.08 & & & 2.1 & & & 0.11 & \\
\hline $\operatorname{Pr}>\mathbf{F}$ & $* * *$ & & & * & & & ** & & & $* * *$ & \\
\hline
\end{tabular}

Note. Means with the same letter in the same column are not significantly different $(\mathrm{P}>0.05)$, A1-Percentage grain yield ( $t / h a)$ advantage relative to best check entry.

\subsection{GGE-Biplots}

Genotype and genotype-by-environment interaction (GGE) biplots allow effective identification of the Genotype-by-Environment Interaction (GEI) pattern of the data. In this current study, biplots were plotted for entries in population A and B to allow visualization of, which-won-where patterns pattern for genotypes and environments, genotype-focused scaling for comparison of the genotypes with ideal genotype, environment-focused scaling for comparison of the environments relative to an ideal environment, and average environment coordination (AEC) views based on environment-focused scaling for the means performance and stability of genotypes. Subsequent GGE biplot analysis produced eight biplots for entries in Population A (Figure 1 to 4 ) and Population B (Figures 5 to 8 ) to allow visualization of; which-won-where pattern for genotypes and environments, genotype-focused scaling for comparison of the genotypes with ideal genotype, environment-focused scaling for comparison of the environments relative to an ideal environment, and average environment coordination (AEC) views based on environment-focused scaling for the mean performance and 
stability of genotypes. The biplots consist of PC1 scores plotted against PC2 scores for both genotypes and environments.

\subsection{Genotype Evaluation Using GGE-Biplots for Top 12\% High-Yielding Hybrids in Population A}

Visualization of which-won-where pattern of multi-environment trials data for top $12 \%$ high-yielding experimental single-cross hybrids and checks in Population A is depicted through the polygon views of the GGE-biplot (Figure 1), thus present a summary of the $\mathrm{G} \times \mathrm{E}$ pattern of a multi-environment yield trial data set. The polygon was formed by connecting genotypes' scores $(135,257,60,127,154$, and 281) that are furthest away from the point of origin, resulting in all the other genotypes being confined in the polygon. Six perpendicular lines were drawn starting from the origin and extended beyond the polygon such that the biplot was divided into six sectors, and environments fell into three of them. The winning genotype for each sector is the one located at the respective vertex. Figure 1 illustrates that the Ukulinga Research Station environment fell in a sector in which experimental hybrid entries 135 and 257 were the vertex hybrids. Though there were two vertex hybrids, experimental single-cross hybrid entry 135 was the uniquely adapted hybrid to the Ukulinga Research Station environment. Potchefstroom Research Station environment fell in the sector in which experimental single-cross hybrid entries 127 and 60 were the vertex hybrids, thus indicating that they were the hybrids with the highest expected grain yields for this environment. Cedera Research Station environment did not have a vertex hybrid, an indication that no hybrids were uniquely adapted to this environment. No environments fell into sectors with experimental single-cross hybrid entries 154 and 281 as the vertices, indicating that these maize hybrids were not the best in any environment. Ukulinga Research Centre environment discriminated the genotypes more clearly, as shown by higher PC1 scores. The two PC scores accounted for $35.01 \%$ and $64.76 \%$ of the total GGE variation, respectively. Therefore, the biplot explained $99.77 \%$ of the total variation relative to genotype and genotype-environment interaction, a near-perfect accountability score.

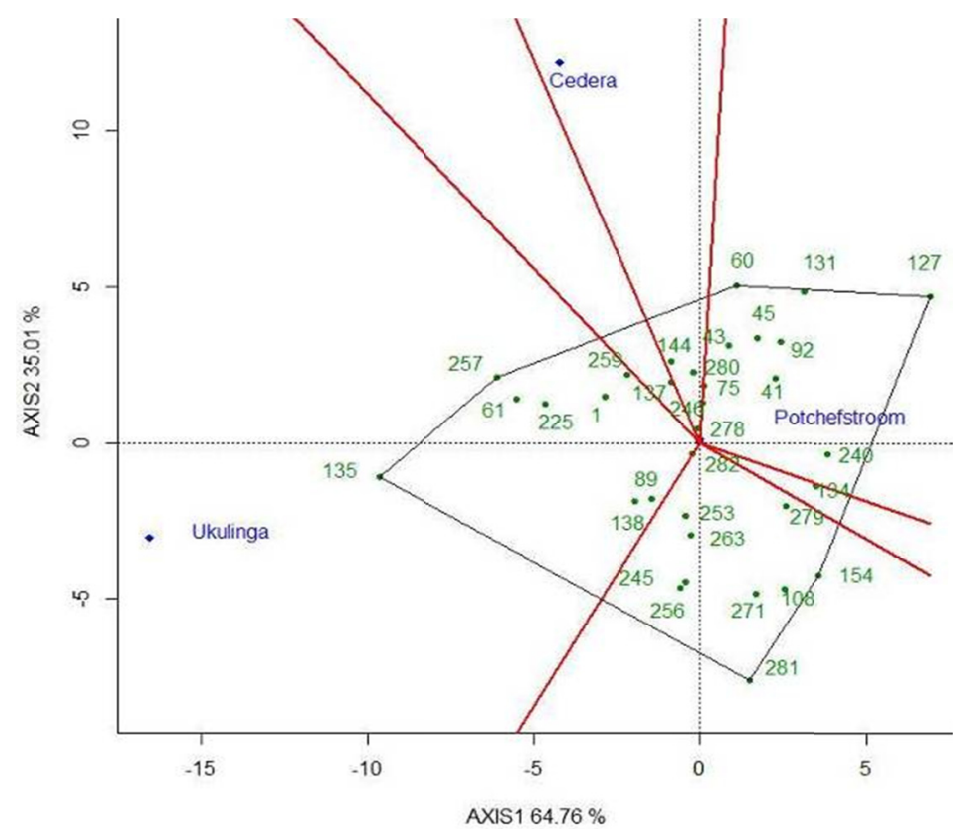

Figure 1. Polygon views of the GGE-biplot based on symmetrical scaling for which-won-where pattern for genotypes and environments for 12\% top-yielding experimental single-cross hybrids and commercial check hybrids per location in Population A. Details of the environments are given in Table 1

Ranking genotypes relative to the ideal genotype illustrates that an ideal genotype should have high mean yield performance and high stability across environments (Jalata, 2011). It is a genotype to be on Average Environment Axis (AEA) on the positive direction and has a vector length equal to the longest vectors of the genotypes on the positive side of AEA with the largest vector length of high yielding genotypes and indicated by an arrow pointed to it (Kaya et al., 2006; Yan \& Tinker, 2006). Therefore, experimental single-cross hybrids and commercial check hybrids located closer to the ideal genotype are more desirable than others. In the current study (Figure 2), experimental single-cross hybrid entry 257 was closest to ideal genotypes in terms of higher-yielding ability and stability relative to the others, thus indicating that it's the most desirable maize hybrid 
for Population A. Experimental single-cross hybrid entry 127 was classified as highly undesirable in this trial, as it was placed furthest away from the ideal concentric circle.

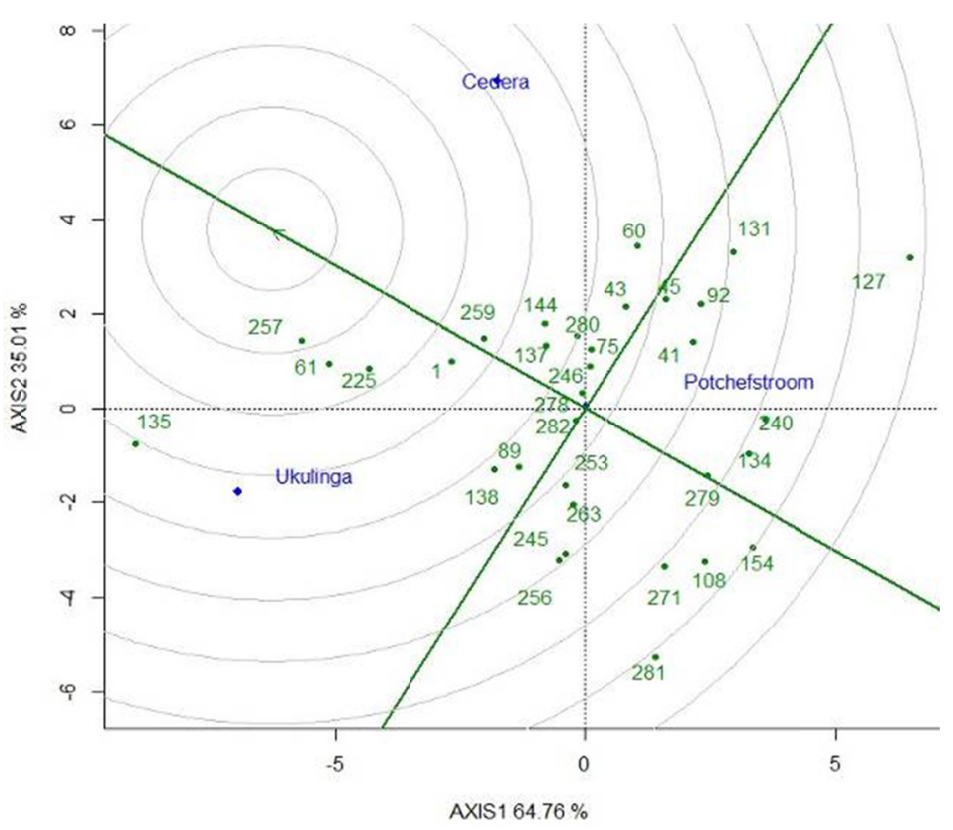

Figure 2. GGE biplot based on genotype-focused scaling for comparison of genotypes with the ideal genotype for $12 \%$ top-yielding experimental single-cross hybrids and commercial check hybrids in Population A based on mean performance and stability

Multi-environment trial data is mostly used for genotype evaluations; the same data can also be used in site evaluations. The ideal test environment should be the most discriminating (informative) and most representative of the target environments and is a good test environment for selecting generally adapted genotypes. The ideal test environment is found in the centre of the concentric circles. It is a point on average-environment-axis (AEA) in the positive direction most (representative) with a distance to the biplot origin equal to the longest vector of all environments (Yan et al., 2001; Jalata, 2011; Frutos et al., 2014; Shim et al., 2015; Dehghani et al., 2009). Under natural conditions, such environments do not exist but can be used relatively as a reference. Thus, the closer a site is to this virtual site, the better it is as a test site. Ukulinga Research Station environment is the most representative as it is closest to this point for Population A (Figure 3). It was a good test environment that had the most discriminating capacity for population A and most representative of the target environments. Contrary to the Ukulinga Research Station environment, Potchefstroom Research Station environment was the least ideal environment for discriminating experimental single-cross hybrids and commercial check hybrids for Population A. 


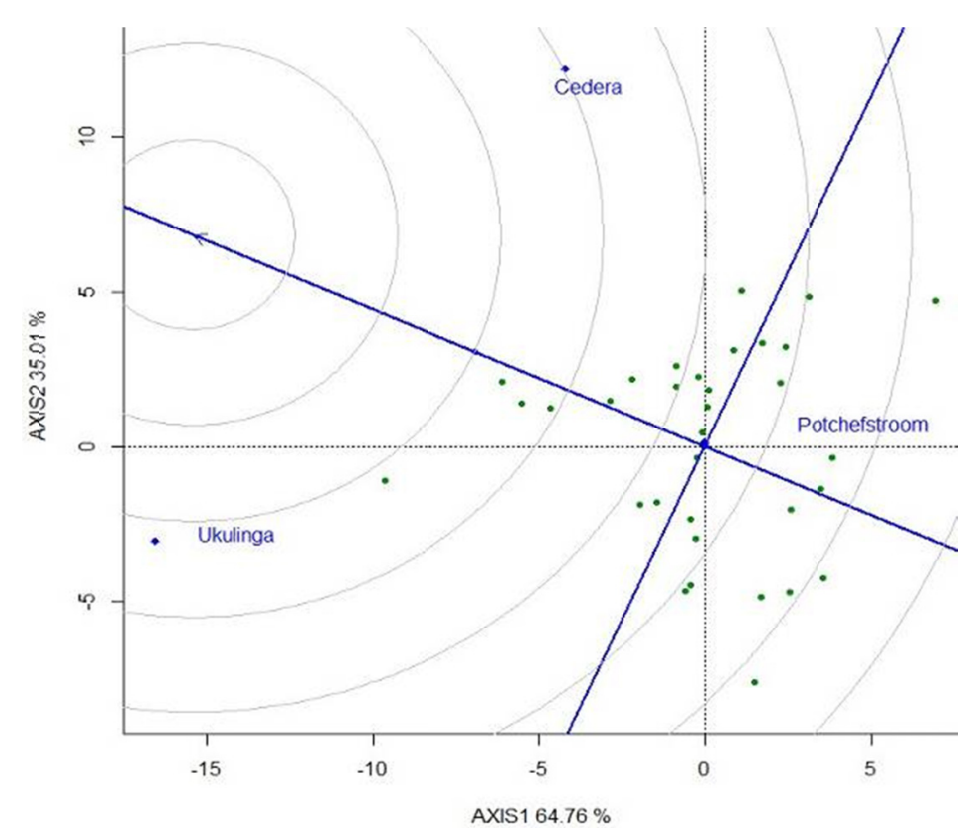

Figure 3. Ranking environments based on discriminating ability and representativeness for $12 \%$ of top-yielding experimental single-cross hybrids and commercial check hybrids in Population A

Figure 4 illustrates the average-environment coordination (AEC) view of the GGE biplot, which represents the single arrowed line as the AEC abscissa (or AEA) and points to higher mean yield across environments (Kaya et al., 2006; Jandong et al., 2011; Dehghani et al., 2009). The average yield of the genotypes is approximated by the projections of their markers on the AEC x-axis. Hence, the top ten experimental single-cross hybrids 257, 61, $225,1,259,137,144,246,43$, and 89 (Figure 4) had the same consistent performance with the actual grain yield of the experimental single-cross hybrids (Table 2). While experimental single-cross hybrids 154 and 135 had the lowest mean yields. The AEC ordinate passes the plot origin and is perpendicular to the AEC abscissa and points to more significant variability (poor stability) in either direction. Hence, experimental single-cross hybrid 135, 281 and 127 were highly unstable. In contrast, experimental single-cross hybrid entry 1 was highly stable across the three environments.

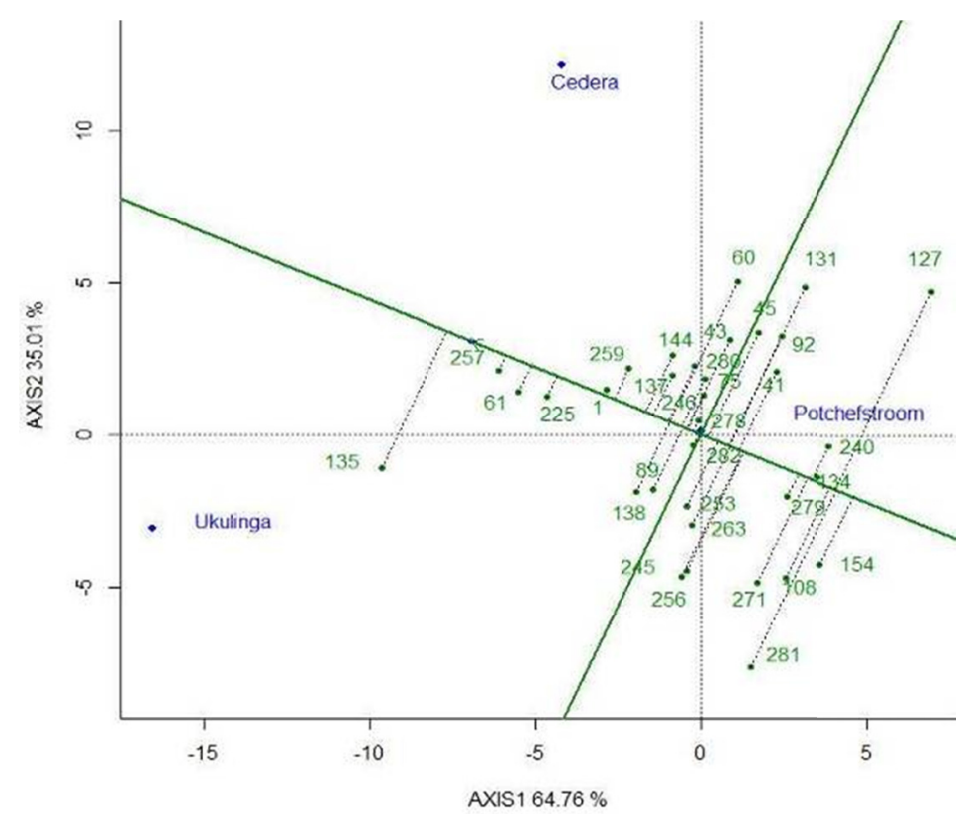

Figure 4. Average-environment coordination (AEC) abscissa view for top 12\% high-yielding experimental single-cross hybrids and commercial check hybrids for Population A 


\subsection{Grain Yield (t/ha) Performance for Top 14\% High-Yielding Hybrids in Population B}

Table 3 shows that data for grain yield ( $\mathrm{t} / \mathrm{ha}$ ) performance for top $14 \%$ top-yielding experimental single-cross hybrids and commercial check hybrids in Population B sorted relative to the average rank for grain yield ( $\mathrm{t} / \mathrm{ha})$ across environments and individual environments (Cedera Research Station, Potchefstroom Research Station and Ukulinga Research Centre). Across the environments, data showed that grain yield ( $t / h a)$ performance was highly significant, with experimental hybrid entries and adapted commercial check hybrids showing significant comparable grain yield ( $\mathrm{t} / \mathrm{ha}$ ) performance. The average rank position for grain yield $(\mathrm{t} / \mathrm{ha})$ performance across environments highlighted that experimental hybrid entry 112 had a $7.3 \%$ grain yield ( $\mathrm{t} / \mathrm{ha}$ ) advantage relative to the best commercial check hybrid (PAN6Q445B). Individual environments, data for the Ukulinga Research Centre environment was not significantly different for grain yield ( $t /$ ha) performance. While, Potchefstroom Research Station environments and Cedera Research Station environments grain yield ( $\mathrm{t} / \mathrm{ha}$ ) performance data was significant with experimental hybrid entries exhibiting comparable performance relative to the adapted temperate environment commercial check hybrids (PAN6Q445B, DK78-45BR, 13XH915, and PAN6611). At Cedera Research Station, average rank position for grain yield ( $\mathrm{t} / \mathrm{ha}$ ) performance highlighted that six experimental single-cross hybrids $(112,123,152,100,121$, and 95) had a better average rank position placement than the adapted best temperate experimental single-cross hybrids (PAN6Q445B). These experimental single-cross hybrids had an 8.6-34.1\% grain yield ( $\mathrm{t} / \mathrm{ha}$ ) advantage relative to the best adapted best commercial check (PAN6Q445B). Equally, at Potchefstroom Research Station environment, five experimental hybrid entries $(117,89,95,113$, and 61) had significant comparable grain yield (t/ha) performance to best adapted temperate environment commercial check hybrids. A 9.2-29.3\% grain yield ( $\mathrm{t} / \mathrm{ha}$ ) advantage relative to best adapted commercial check hybrid (PAN6Q445B).

Table 3. Grain yield performance for top $14 \%$ high-yielding experimental single-cross hybrids and commercial check hybrid in Population B across and individual environments

\begin{tabular}{|c|c|c|c|c|c|c|c|c|c|c|c|}
\hline Entry & Across & A1 & Entry & Ukulinga & A1 & Entry & Cedera & A1 & Entry & Potchefstroom & A1 \\
\hline 112 & $7.50 \mathrm{a}$ & 7.34 & 18 & $7.74 a$ & 1.68 & 112 & $14.47 \mathrm{a}$ & 34.11 & 117 & $3.31 \mathrm{a}$ & 29.34 \\
\hline 95 & $6.83 \mathrm{a}$ & -2.26 & 1 & $7.42 \mathrm{a}$ & -2.53 & 123 & $12.88 \mathrm{ab}$ & 19.37 & 89 & $3.09 \mathrm{a}$ & 20.75 \\
\hline 123 & $6.54 \mathrm{a}$ & -6.45 & 153 & $7.41 \mathrm{a}$ & -2.60 & 152 & $12.61 \mathrm{ab}$ & 16.82 & 95 & $3.08 \mathrm{a}$ & 20.16 \\
\hline 100 & $6.43 \mathrm{a}$ & -7.94 & 112 & $7.36 \mathrm{a}$ & -3.32 & 100 & $12.56 \mathrm{ab}$ & 16.40 & 113 & $2.99 \mathrm{a}$ & 16.84 \\
\hline 121 & $5.91 \mathrm{a}$ & -10.68 & 33 & $7.28 \mathrm{a}$ & -4.37 & 121 & $12.01 \mathrm{ab}$ & 11.26 & 61 & $2.80 \mathrm{a}$ & 9.22 \\
\hline 152 & $5.79 \mathrm{a}$ & -18.64 & 110 & $6.94 a$ & -8.77 & 95 & $11.72 \mathrm{ab}$ & 8.62 & 153 & $2.34 \mathrm{a}$ & -8.75 \\
\hline 110 & $5.58 \mathrm{a}$ & -19.72 & 95 & $5.94 \mathrm{a}$ & -21.91 & 153 & $9.51 \mathrm{abc}$ & -11.91 & 121 & $2.24 \mathrm{a}$ & -12.65 \\
\hline 1 & $5.36 \mathrm{a}$ & -22.47 & 101 & $5.23 \mathrm{a}$ & -31.24 & 61 & $9.20 \mathrm{abc}$ & -14.74 & 123 & $2.23 \mathrm{a}$ & -13.04 \\
\hline 33 & $5.32 \mathrm{a}$ & -23.31 & 123 & $4.75 \mathrm{a}$ & -37.55 & 110 & $9.08 \mathrm{abc}$ & -15.85 & 100 & $2.02 \mathrm{a}$ & -21.05 \\
\hline 153 & $5.18 \mathrm{a}$ & -24.13 & 100 & $4.60 \mathrm{a}$ & -39.59 & 89 & $8.68 \mathrm{abc}$ & -19.60 & 1 & $1.95 \mathrm{a}$ & -23.98 \\
\hline 89 & $5.15 \mathrm{a}$ & -25.24 & 117 & $4.60 \mathrm{a}$ & -39.59 & 101 & $8.54 a b c$ & -20.85 & 110 & $1.73 \mathrm{a}$ & -32.38 \\
\hline 113 & $5.02 \mathrm{a}$ & -28.42 & 152 & $4.29 \mathrm{a}$ & -43.59 & 113 & $8.40 \mathrm{abc}$ & -22.20 & 152 & $1.73 \mathrm{a}$ & -32.38 \\
\hline 117 & $4.74 \mathrm{a}$ & -35.16 & 89 & $4.25 \mathrm{a}$ & -44.19 & 1 & $8.36 \mathrm{abc}$ & -22.52 & 112 & $1.61 \mathrm{a}$ & -37.07 \\
\hline 101 & $4.36 \mathrm{a}$ & -36.43 & 113 & $4.24 \mathrm{a}$ & -44.32 & 117 & $7.16 \mathrm{abc}$ & -33.69 & 93 & $1.23 \mathrm{a}$ & -52.10 \\
\hline 61 & $4.25 \mathrm{a}$ & -38.04 & 121 & $3.83 \mathrm{a}$ & -49.70 & 93 & $6.94 \mathrm{abc}$ & -35.73 & 98 & $0.93 \mathrm{a}$ & -63.55 \\
\hline 18 & $4.20 \mathrm{a}$ & -38.15 & 98 & $3.62 \mathrm{a}$ & -52.40 & 33 & $6.68 \mathrm{abc}$ & -38.09 & 18 & $0.621 \mathrm{a}$ & -75.74 \\
\hline 93 & $3.71 \mathrm{a}$ & -40.80 & 93 & $3.60 \mathrm{a}$ & -52.73 & 98 & $4.83 \mathrm{abc}$ & -55.28 & 33 & $0.61 \mathrm{a}$ & -76.32 \\
\hline 98 & $3.52 \mathrm{a}$ & -44.94 & 61 & $2.40 \mathrm{a}$ & -68.50 & 18 & $3.25 \mathrm{bc}$ & -69.88 & 101 & $0.57 \mathrm{a}$ & -77.69 \\
\hline Mean of population & $4.58 \mathrm{a}$ & & & $4.47 \mathrm{a}$ & & & $7.86 \mathrm{abc}$ & & & $1.45 \mathrm{a}$ & \\
\hline Mean of checks & $5.88 \mathrm{a}$ & & & $5.83 \mathrm{a}$ & & & $10.17 \mathrm{abc}$ & & & $2.17 \mathrm{a}$ & \\
\hline Check 3 (SC633) & $5.83 \mathrm{a}$ & & & $4.81 \mathrm{a}$ & & & $12.93 \mathrm{ab}$ & & & $1.94 \mathrm{a}$ & \\
\hline Check 5 (DK78-45BR) & $4.87 \mathrm{a}$ & & & $6.19 \mathrm{a}$ & & & 7.09abc & & & $2.18 \mathrm{a}$ & \\
\hline Check 4 (13XH915 & $5.37 \mathrm{a}$ & & & $4.64 \mathrm{a}$ & & & $9.795 \mathrm{abc}$ & & & $1.96 \mathrm{a}$ & \\
\hline Check 1 (PAN6611) & $6.22 \mathrm{a}$ & & & $5.95 \mathrm{a}$ & & & $10.25 \mathrm{abc}$ & & & $2.24 \mathrm{a}$ & \\
\hline Check 2 (PAN6Q445B) & $6.99 \mathrm{a}$ & & & $7.61 \mathrm{a}$ & & & $10.79 \mathrm{abc}$ & & & $2.56 \mathrm{a}$ & \\
\hline $\operatorname{LSD}_{(0.05)}$ & 0.02 & & & 0.78 & & & 1.05 & & & 0.44 & \\
\hline $\mathrm{CV}$ & 26.88 & & & 38.05 & & & 17.38 & & & 14.08 & \\
\hline St dev & 0.53 & & & 1.66 & & & 1.9 & & & 0.72 & \\
\hline St error & 0.16 & & & 2.22 & & & 1.39 & & & 0.66 & \\
\hline $\operatorname{Pr}>\mathbf{F}$ & $* *$ & & & NS & & & * & & & * & \\
\hline
\end{tabular}

Note. Means with the same letter in the same column are not significantly different $(\mathrm{P}>0.05)$, A1-Percentage grain yield ( $t / h a)$ advantage relative to best check entry. 


\subsection{Genotype Evaluation Using GGE-Biplots for Top 14\% High-Yielding Hybrids in Population B}

Figure 5 shows the GGE-biplot visualization of which-won-where pattern of the multi-environment trials data for the top 14\% high-yielding experimental single-cross hybrids and commercial check hybrids in Population B. The two PC scores accounted for $78.78 \%$ and $21.22 \%$ of the total GGE variation, respectively. Therefore, the biplot explained $100 \%$ of the total variation relative to genotype and genotype-environment interaction, a perfect accountability score. A polygon was formed by connecting scores of experimental single-cross hybrids 112,152 , $121,61,117$, and 18 that are furthest away from the point of origin, resulting in all the other genotypes being confined in the polygon. Six perpendicular lines were drawn starting from the origin and extended beyond the polygon. The biplot was divided into six sectors, and the environments fell into three of the sectors. Ukulinga Research Station environment fell in the sector in which experimental hybrid entries 18 was the vertex hybrid. Thus, indicating that it was a uniquely adapted hybrid to the Ukulinga Research Station environment. Potchefstroom Research Station environment fell in the sector where experimental single-cross hybrid entry 117 was the vertex hybrid, indicating that it was the "winner" in the Potchefstroom Research Station environment. Cedera Research Station environment had experimental single-cross hybrid entry 112 as the vertex hybrid, an indication that it was uniquely adapted to this environment. No environments fell into sectors with experimental single-cross hybrids 121 and 61 as the vertices, indicating that these maize hybrids were not the best in any environment.

GGE biplot based on genotype-focused scaling for comparison of genotypes with the ideal genotype for Population B based on mean performance and stability accounted for $100 \%$ of the total variation relative to genotype genotype-by-environment interaction, which is a perfect level of accountability (Figure 6). Ranking genotypes relative to the ideal genotype for the top $14 \%$ high-yielding experimental single-cross hybrids and commercial check hybrids illustrates that the arrow is where the ideal experimental single-cross hybrid entry or commercial check hybrid should be. Thus, experimental single-cross hybrid entry 121 was placed in the concentric circle closest to ideal genotypes in terms of higher-yielding ability and stability relative to the others, thus indicating that it's the most desirable maize hybrid for Population B. Experimental single-cross hybrid entry 18 was classified as highly undesirable in this trial, as it was placed furthest away from the ideal concentric circle.

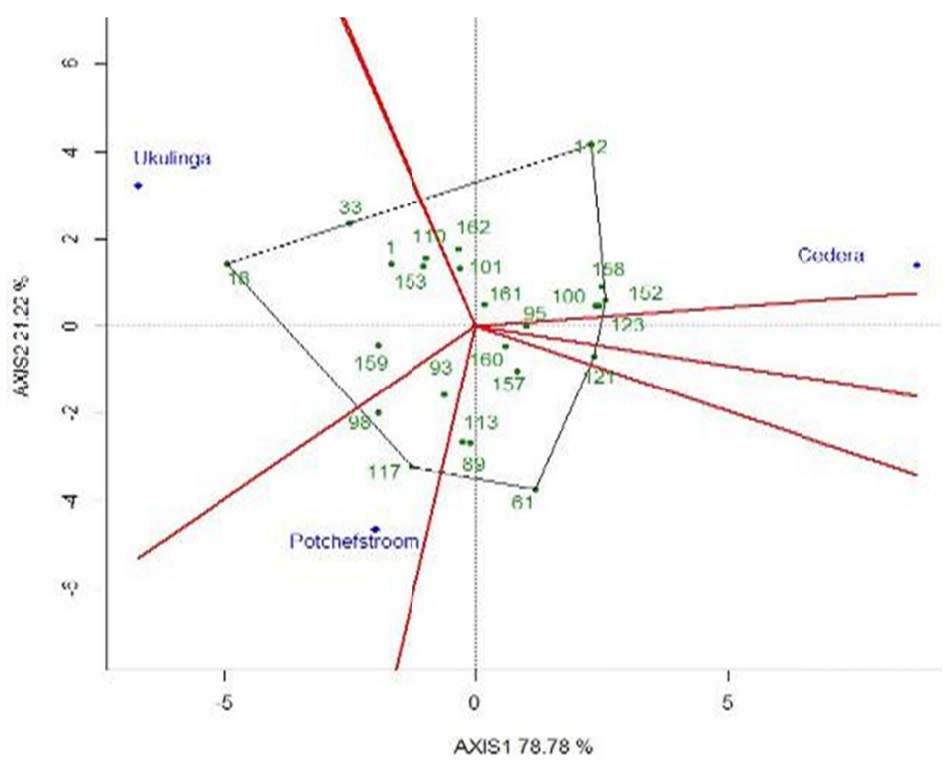

Figure 5. Polygon views of the GGE-biplot based on symmetrical scaling for which-won-where pattern for genotypes and environments for $12 \%$ top-yielding experimental hybrids and checks per location in Population B. Details of the environments are given in Table 1 


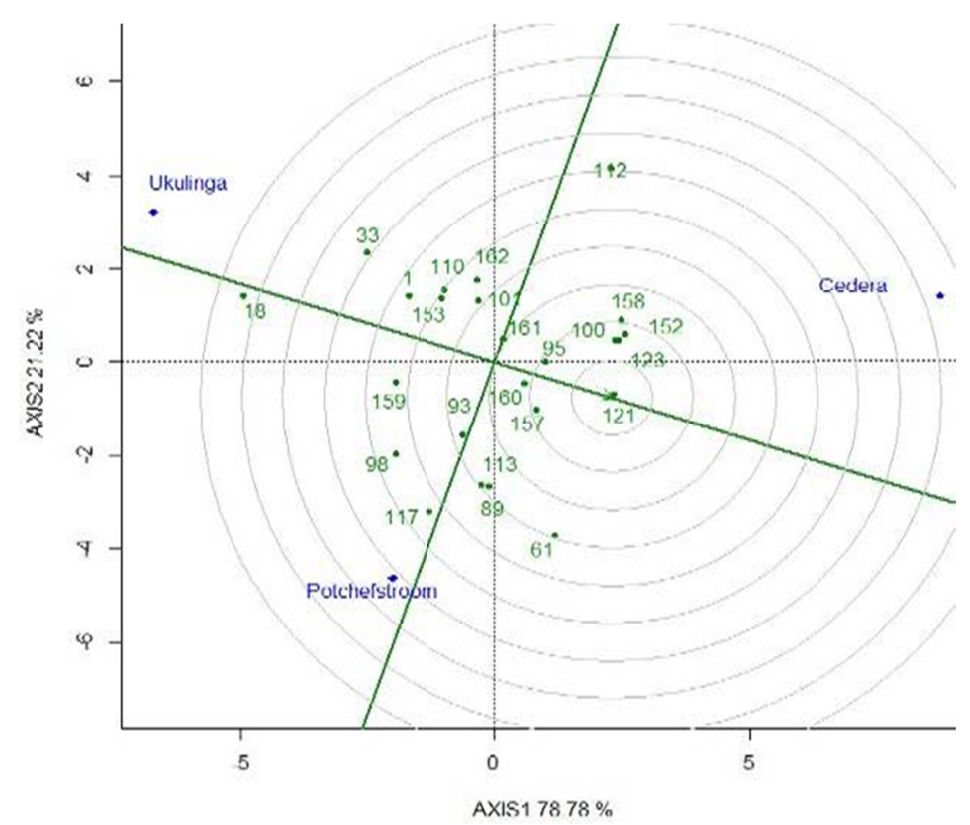

Figure 6. GGE biplot based on genotype-focused scaling for comparison of genotypes with the ideal genotype for top 14\% top-yielding experimental hybrids and checks in Population B based on mean

performance and stability

Figure 7 shows GGE-biplot of PC2 and PC1 based on environment-focused scaling for comparison of the environments with the ideal environment for Population B. Cedara Research Station environment was classified as the ideal testing environment that was the most discriminating for Population B as it was the nearest to the centre of the concentric circles. Ukulinga Research Centre and Potchefstroom Research Station environments were placed within the concentric circles that were defined as favourable environments, indicating high yield potential for the Population B trial.

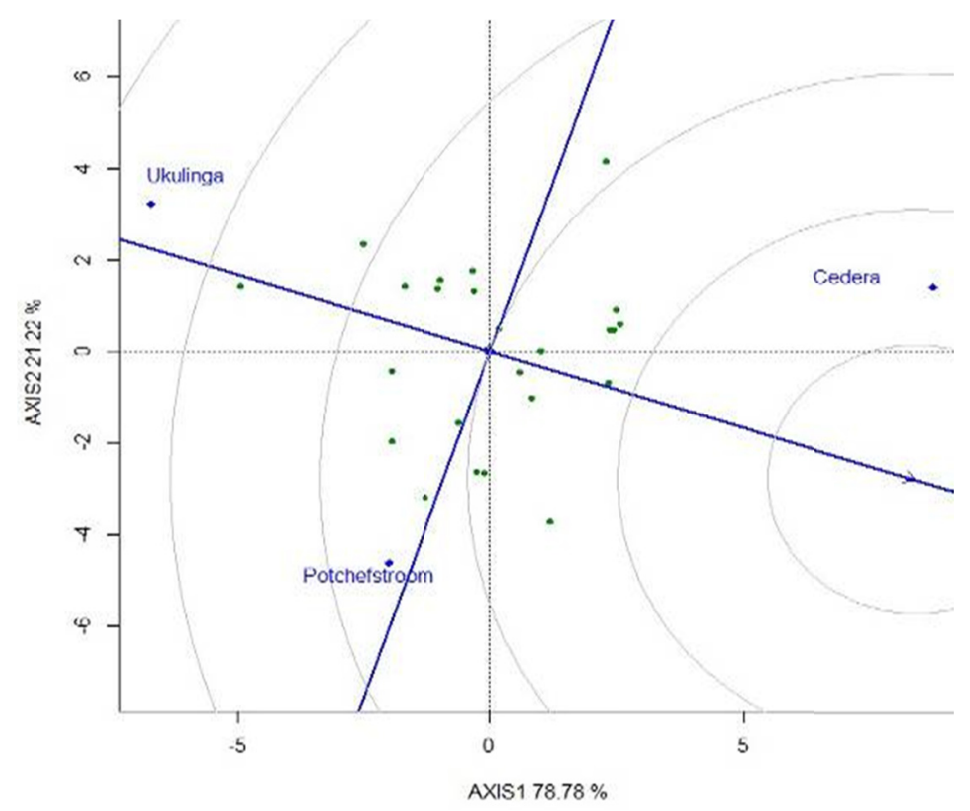

Figure 7. Ranking environments based on discriminating ability and representativeness for $14 \%$ of top-yielding experimental single-cross hybrids and commercial check hybrids-in Population B 


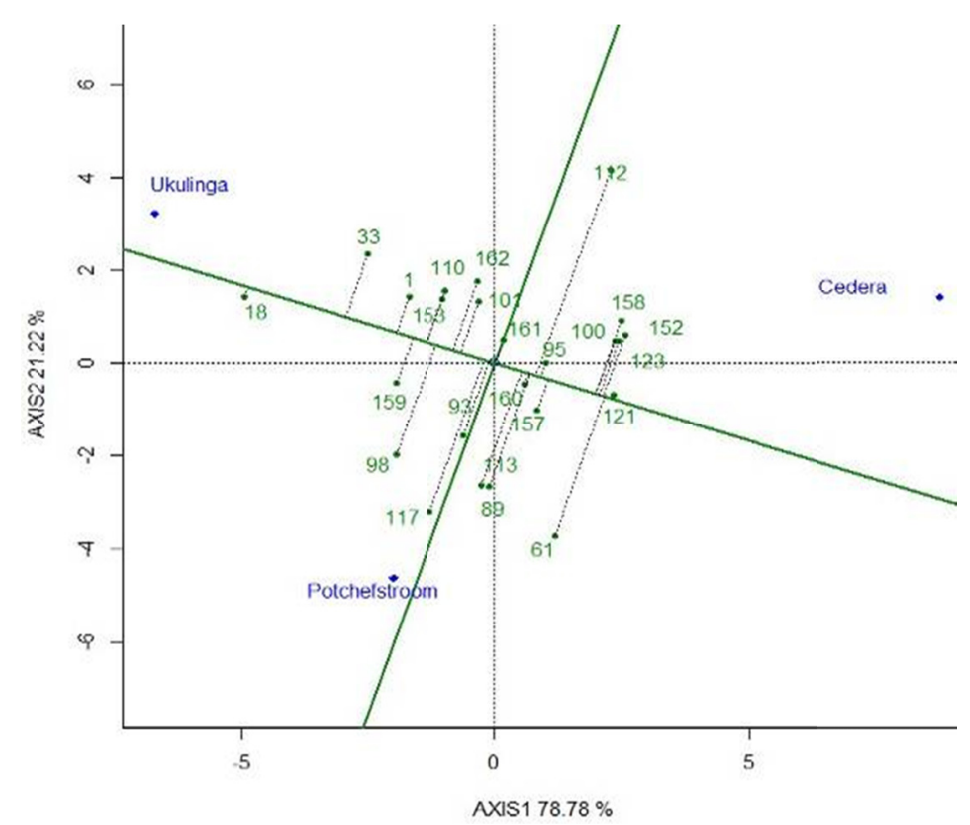

Figure 8. Average-environment coordination (AEC) abscissa view for top 14\% high-yielding hybrids for Population A

Average-environment coordination (AEC) abscissa view for top 14\% high-yielding experimental single-cross hybrids and commercial check hybrids for Population A (Figure 8), which represents the single arrowed line as the AEC abscissa (or AEA) and points to higher mean yield across environments. Thus, experimental single-cross hybrid 112 had the highest mean yield, followed by experimental single-cross hybrids 100, 123, 95, and 112 that had the same consistent performance with actual grain yield of the experimental single-cross hybrids (Table 3) for Population B. Contrary; experimental single-cross hybrid entry 18 had the lowest mean yield. The AEC ordinate passes the plot origin and is perpendicular to the AEC abscissa and points to more significant variability (poor stability) in either direction. Hence, experimental single-cross hybrids 117 and 112 were highly unstable. In contrast, experimental single-cross hybrid 161 was highly stable across the three environments.

\section{Discussion}

\subsection{Grain Yield (t/ha) Performance for Selected Experimental Hybrids and Checks in Population A and B}

In the current study, data for grain yield ( $t / h a)$ performance for experimental single-cross hybrids and commercial check hybrids in population A and B across environments and individual environments identified entries that had significant comparable grain yield ( $t /$ ha) performance relative to best commercial check hybrid on the market. These experimental single-cross hybrids not only exhibited significant comparable grain yield $(\mathrm{t} / \mathrm{ha})$ performance but had a better average rank position for grain yield ( $\mathrm{t} / \mathrm{ha}$ ) across environments and individual environments. The experimental single-cross hybrids exhibited that there were different winning genotypes in each environment. Thus, providing positive exploitation of the Genotype-Environment (GE) interaction. Selected experimental single-cross hybrids at each site and across environment can also be advanced for further evaluation with a possibility for identifying high yielding experimental hybrid entries for variety registration and release. Farmers can quickly adopt such experimental single-cross hybrids in target environments if they also have desired economic traits; ear prolificacy, good standability, and early maturity (evaluation of these economic traits will be carried out in future studies) that are required in target environments. Similar results have been reported in hybrid maize varieties at individual sites and across environments highlighting an opportunity for exploitation of GE interaction to identify hybrid maize varieties that have specific adaptation and stability across environments by Dehghani et al. (2007), Balestre et al. (2009), Alwala et al. (2010), and de Oliveira et al. (2010).

Population A top four experimental single-cross hybrids $(225,89,246$, and 43$)$ across environments had a better rank position for average grain yield ( $t / h a)$ performance and $(0.9$ to $6.7 \%)$ grain yield $(t / h a)$ advantage over the best adapted commercial check hybrid (PAN6Q445B). Similarly, for Population B across environments, experimental single-cross hybrid 112 had the best rank position for grain yield (t/ha) and a 7.3\% grain yield (t/ha) 
advantage over the best adapted commercial check hybrid (PAN6Q445B). Average grain yield ( $t /$ ha) performance across environments are good indicators of genotypic performance only in the absence of Genotype-by-Environment Interaction (Kaya et al., 2006; Balestre et al., 2009). Thus, indicating that these experimental single-cross hybrids have the potential to be advanced for further evaluation, possible registration, and release in target environments. These selected experimental single-cross hybrids also allow an opportunity to explore what makes these hybrids unique and whether they have shared desired economic traits, i.e., physiological maturity, drought tolerance, prolificacy, and good standability that is valuable in advancing this breeding program.

Individual environments data for average rank position grain yield $(\mathrm{t} / \mathrm{ha})$ performance for Population A experimental single-cross hybrids was significantly comparable to adapted commercial check hybrids across all the environments (Cedera Research Station, Ukulinga Research Centre, and Potchefstroom Research Station environments. Contrary, Population B had Cedera Research Station and Potchefstroom Research Station environments as significant environments. Population A data highlighted that at Cedera Research Station environment top-placed experimental single-cross hybrids had 0.4 to $12.1 \%$ grain yield (t/ha) advantage over the best adapted commercial check (PAN6Q445B). At the Ukulinga Research Station environment, the best-placed experimental hybrids had a 4.4 to $97.9 \%$ grain yield ( $t /$ ha) advantage over the best commercial check (PAN6Q445B). In comparison, Potchefstroom Research Station environment noted a 3.16 to $3.86 \%$ grain yield ( $t /$ ha) advantage for the best placed experimental hybrids relative to best adapted commercial check hybrid (PAN6Q445B). Population B data showed that at the Cedera Research Station environment, the best-placed six experimental single cross hybrids had an $8.6-34.1 \%$ grain yield ( $\mathrm{t} / \mathrm{ha}$ ) advantage relative to the best-adapted check (PAN6Q445B).

Similarly, at the Potchefstroom Research Station environment's top five experimental single-cross hybrid entries had a $9.2-29.3 \%$ grain yield advantage over the best-adapted commercial check hybrid (PAN6Q445B). This group of selected experimental single-cross hybrids for both Population A and B can be advanced for further testing as they can out-compete adapted commercial check hybrids. Thus, indicating a possibility for commercial registration and release if they are to maintain consistent performance is accompanied by desired economic traits (prolificacy, early physiological maturity, and good standability) for target environments. These experimental single-cross hybrids also provide an opportunity for the breeding program to explore if they have unique traits that can be utilized in advancing the breeding program.

\subsection{GE-Biplots Patterns}

Visualization of which-won-where pattern of multi-environmental trials data is essential for studying the possible existence of different mega environment (ME) in a region (Gauch, 2006; Kaya et al., 2006; Jalata et al., 2009; Alwala et al., 2010; Jandong et al., 2011; Shim et al., 2015). In this study, visualization of which-won-where pattern of multi-environment trials data for experimental single-cross hybrids and commercial check hybrids in Population A illustrated that there were six sectors and environments fell into three of them. Two of the environments, Potchefstroom Research Station and Ukulinga Research Station, had experimental single-cross hybrids 127 and 135 as the vertex hybrids. Most importantly, the vertex hybrids had higher (sometimes the highest) grain yield (t/ha) than the other hybrids (experimental single-cross hybrids and commercial check hybrids) in all environments that fell in these sectors. Similar results were also reported by (Crossa et al., 2002; Kaya et al., 2006). Cedera Research Station environment did not have a vertex hybrid, an indication that no hybrid was ideal for this environment. Population B data also had six sectors, and the environments fell into three of them. Cedera Research Station, Ukulinga Research Station, and Potchefstroom Research Station environments had experimental single-cross hybrids 112,117, and 18 as the vertex hybrids. Thus, indicating that these were the winning hybrids for each respective environment for both Population A and B, with Ukulinga Research Station environment discriminating the genotypes more clearly as depicted by higher PC1 scores. GGE biplot analysis carried out on Population A, and B identified sites that best represent the target environment for these populations. Several similar studies (Balestre et al., 2009; Jalata, 2011; Kaya et al., 2006; Ndhlela, 2012; Yan et al., 2010) have been conducted across crops not only to identify high yielding cultivars but also to identify sites that best represent the target environments. Selected experimental single-cross hybrids for both Population A (127 and 135) and B (112,117 and 18) in this current study can be advanced for further evaluation in the subsequent seasons with a possibility for variety registration and release their selected target environments. 


\subsection{Ideal Genotypes}

According to Kaya et al. (2006), and Dehghani et al. (2009), yield potential and stability of genotypes are evaluated by an average environment coordination (AEC) method. In this method, an average environment is defined by the average PC1 and PC2 scores of all the environments. An ideal genotype should have the highest mean grain yield ( $t / h a)$ performance and stability across all the environments and may not exist but can be used as a reference for genotype evaluation (Yan and Tinker, 2006). In Population A, experimental single-cross hybrid 257 was close to ideal, while experimental single-cross hybrid 127 was the highly undesirable entry. In Population B, experimental single-cross hybrid 121 was defined as the ideal genotype, and in contrast, experimental single-cross hybrid 18 was defined as the highly undesirable entry. The ideal experimental single-cross hybrids in Population A (257) and B (121) can be used in future similar projects as a reference in selecting for maize genotypes that are defined as ideal genotypes.

\subsection{Ideal Environment}

An ideal testing environment should have the ability to discriminate genotypes in terms of the main genotypic effect during evaluation. This environment should have large PC1 scores and small PC2 scores, together with approach $100 \%$, and may not exist in reality, but it can be used as a reference for genotype selection in multi-location trials (Kaya et al., 2006). In Population A and B, both environments were not ideal environments for these entries. However, they can be used to define the most favourable environment that can be used for evaluating high yield potential. In the current study, Ukulinga Research Station was defined as the ideal environment for Population A. In comparison, Cedera Research Station was defined as the ideal environment for Population B.

\subsection{Mean Yield and Stability of the Genotypes}

Average-environment coordination (AEC) view of the GGE biplot in Population A indicated that experimental hybrid entry 1 was highly stable across the three environments. While experimental single-cross hybrids 135 , 281 and 127 were highly unstable highly stable across the three environments. Population B, experimental single-cross hybrid 161, was highly stable across environments. In contrast, experimental single-cross hybrid 117 and 112 were highly unstable across the three environments.

\section{Conclusion}

Experimental single-cross hybrids 225, 89, 246, and 43 in Population A and 112 in Population B had better average rank position for grain yield ( $t /$ ha) performance across environments and grain yield $(t / h a)$ grain yield ( $t /$ ha) advantage over the best adapted commercial check hybrid (PAN6Q445B) of $0.9-6.7 \%$ and $7.3 \%$ for Population A and B, respectively. These selected experimental single-cross hybrids can also be advanced for further evaluation with a possibility for identifying high yielding experimental single-cross hybrids for variety registration and release in target environments in South Africa if they even have desired economic traits. In terms of stability, experimental single-cross hybrids 1 and 161 in populations A and B, respectively, were defined as highly stable hybrids across environments. Experimental single-cross hybrids 257 (Population A) and 121 (Population B) were identified as the ideal hybrids.

\section{References}

Alwala, S., Kwolek, T., McPherson, M., Pellow, J., \& Meyer, D. (2010). A comprehensive comparison between Eberhart and Russell joint regression and GGE biplot analyses to identify stable and high yielding maize hybrids. Field Crops Research, 119, 225-230. https://doi.org/10.1016/j.fcr.2010.07.010

Balestre, M., de Souza, J. C., Pinho, R. G. V., de Oliveira, R. L., \& Paes, J. M. V. (2009). Yield stability and adaptability of maize hybrids based on GGE biplot analysis characteristics. Crop Breeding and Applied Biotechnology, 9, 219-228. https://doi.org/10.12702/1984-7033.v09n03a03

CIMMYT. (1985). Managing Trials and Reporting Data for CIMMYT's International Maize Testing Program. Mexico, DF.

Crossa, J., Cornelius, P. L., \& Yan, W. (2002). Biplots of linear-bilinear models for studying cross over genotype $\times$ environment interaction. Crop Science, 42, 619-633. https://doi.org/10.2135/cropsci2002.6190

Dehghani, H., Sabaghnia, N., \& Moghaddam, M. (2009). Interpretation of genotype-by-environment interaction for late maize hybrids' grain yield using the biplot method. Turkey Journal of Agriculture Forum, 33, 139-148.

Duarte, J. B., \& Vencovsky, R. (1999). Interação genótipos $\times$ ambientes. Uma Introdução à análise AMMI. Série Monografias 9 (pp. 46-72). ESALQ/USP, Ribeirão Preto, SP. 
Elias, A. A., Robbins, K. R., Doerge, R. W., \& Tuinstra, R. M. (2016). Half a Century of Studying Genotype $\times$ Environment Interactions in Plant Breeding Experiments. Crop Science, 56(5), 2090-2105. https://doi.org/ 10.2135/cropsci2015.01.0061

Frutos, E., Galindo, M. P., \& Leiva, V. (2014). An interactive biplot implementation in R for modelling genotype-by-environment interaction. Stochastic Environmental Research and Risk Assessment, 28, 1629-1641. https://doi.org/10.1007/s00477-013-0821-z

Gauch, H. G. (2006). Statistical analysis of yield trials by AMMI and GGE. Crop Science, 46, 1488-1500. https://doi.org/10.2135/cropsci2005.07-0193

Gauch, H. G., Piepho, H. P., \& Annicchiarico, P. (2008). Statistical analysis of yield trials by AMMI and GGE: further considerations. Crop Science, 48, 866-889. https://doi.org/10.2135/cropsci2007.09.0513

Genstat 14th Edition. (2013). Retrieved September 11, 2013, from http://www.genstat.co.uk

George, N., \& Lundy, M. (2019). Quantifying Genotype $\times$ Environment Effects in Long-Term Common Wheat Yield Trials from an Agroecologically Diverse Production Region. Crop Science, 59(5), 1960-1972. https://doi.org/10.2135/cropsci2019.01.0010

Heidari, S., Azizinezhad, R., \& Haghparast, R. (2016). Yield stability analysis in advanced durum wheat genotypes by using AMMI and GGE biplot models under diverse environments. Indian Journal of Plant Breeding and Genetics, 76(3), 274-283. https://doi.org/10.5958/0975-6906.2016.00042.0

Jalata, Z. (2011). GGE-biplot analysis of Multi-environment yield trials of Barley (Hordeium vulgare L.) Genotypes in Southeastern Ethiopia Highlands. International Journal of Plant Breeding and Genetics, 5(1), 59-75. https://doi.org/10.3923/ijpbg.2011.59.75

Jandong, E. A., Uguru, M. I., \& Oyiga, B. C. (2011). Determination of yield stability of seven soybeans (Glycine max) genotypes across diverse soil pH levels using GGE biplot analysis. Journal of Applied Biosciences, 43, 2924-2941.

Kaya, Y., Akcura, M., \& Taner, S. (2006). GGE-Biplot Analysis of Multi-Environment Yield Trials in Bread Wheat. Turkey J. Agriculture Forum, 30, 325-337.

Kuchanur, P. H., Salimath, P. M., Wali, M. C., \& Hiremath, C. (2015). GGE biplot analysis for grain yield of single-cross maize hybrids under stress and non-stress conditions. Indian Journal of Plant Breeding and Genetics, 75(4), 514-517. https://doi.org/10.5958/0975-6906.2015.00082.6

Lin, C. S., \& Poushinsky, G. (1983). A Modified Augmented Design for an Early Stage of Plant Selection Involving a Large Number of Test Lines without Replication Author A Modified Augmented Design for an Early Stage of Plant Selection Involving a Large Number of Test Lines without Replication. Biometrics, 39 , 553-56. https://doi.org/10.2307/2531083

Mostafavi, K., Imeni, S. H., \& Zare, M. (2011). Stability analysis of rice genotypes based GGE biplot Method in North of Iran. Journal of Applied Sciences Research, 7, 1690-1694.

Oliveira, R. L., Pinho, R. G. V., Balestre, M., \& Ferreira, D. V. (2010). Evaluation of maize hybrids and environmental stratification by the methods AMMI and GGE biplot. Crop Breeding and Applied Biotechnology, 10, 247-253. https://doi.org/10.1590/S1984-70332010000300010

Scott, R. A., \& Milliken, G. A. (1993). A SAS Program for Analyzing Augmented Randomized Complete-Block Designs. Crop Science, 33, 865-867. https://doi.org/10.2135/cropsci1993.0011183X003300040046x

Setimela, P. S., Magorokosho, C., Lunduka, R., Gasura, E., Makumbi, D., Tarekegne, A., ... Mwangi, W. (2017). On-Farm Yield Gains with stress-tolerant Maize in Eastern and Southern Africa. Agronomy Journal, 109(2), 406-417. https://doi.org/10.2134/agronj2015.0540

Shim, K. B., Shin, S. H., Shon, J. Y., Kang, S. G., Yang, W. H., \& Heu, S. G. (2015). Interpretation of Genotype $\times$ Environment Interaction of Sesame Yield Using GGE Biplot Analysis. Korean Journal of Crop Science, 60(3), 349-354. https://doi.org/10.7740/kjcs.2015.60.3.349

Spehar, C. R. (1994). Field screening of soya bean (Glycine max (L.) Merrill) germplasm for aluminium tolerance by the use of augmented design. Euphytica, 76, 203-213. https://doi.org/10.1007/BF00022165

Syngenta Foundation for Sustainable Agriculture. (2020). Syngenta, South Africa. Retrieved November 14, 2020, from https://www.syngenta.co.za 
Yan, W., \& Hunt, L. A. (2001). Interpretation of Genotype $\times$ Environment Interaction for Winter Wheat Yield in Ontario. Crop Science, 41(1), 19-25. https://doi.org/10.2135/cropsci2001.41119x

Yan, W., \& Tinker, N. A. (2006). Biplot analysis of multi-environment trial data: Principles and applications. Canadian Journal of Plant Science, 86, 623-645. https://doi.org/10.4141/P05-169

Yan, W., Hunt, L. A., Sheng, Q., \& Szlavnics, Z. (2000). Cultivar evaluation and mega-environment investigation based on the GGE biplot. Crop Science, 40, 597-605. https://doi.org/10.2135/cropsci2000. $403597 x$

Yan, W., Kang, M. S., Ma, B., Woods, S., \& Cornelius, P. L. (2007). GGE Biplot vs AMMI Analysis of Genotype-by-Environment Data. Crop Science, 47, 643-653. https://doi.org/10.2135/cropsci2006.06.0374

Yu, P. (2010). How to Convert Mean Separation Output to Letter Groupings in Proc Mixed: A Tip for Statistical Analysis. Department of Animal and Poultry Science College of Agriculture and Bioresources, University of Saskatchewan, Canada.

\section{Copyrights}

Copyright for this article is retained by the author(s), with first publication rights granted to the journal.

This is an open-access article distributed under the terms and conditions of the Creative Commons Attribution license (http://creativecommons.org/licenses/by/4.0/). 